\title{
A Protective Kidney-Lung Approach to Improve Outcomes in Mechanically Ventilated Patients
}

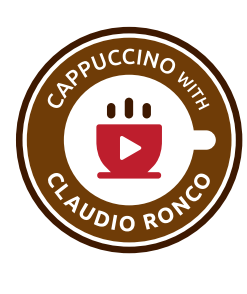

\author{
Faeq Husain-Syed ${ }^{a}$ b Horst-Walter Birk ${ }^{a} \quad$ Werner Seeger $^{a}$ Claudio Ronco $^{b}$ \\ ${ }^{a}$ Department of Internal Medicine II, Division of Pulmonology, Nephrology and Critical Care Medicine, University \\ Clinic Giessen and Marburg, Campus Giessen, Giessen, Germany; ${ }^{b}$ Department of Nephrology, Dialysis and \\ Transplantation, International Renal Research Institute of Vicenza (IRRIV), San Bortolo Hospital, Vicenza, Italy
}

\section{Key Words}

Acute kidney injury - Acute respiratory distress syndrome . Fluid overload $\cdot$ Mechanical ventilation

\begin{abstract}
There is increasing evidence that deleterious interactions between the lung and the kidney may be partly responsible for the multiorgan failure and high mortality seen in patients with acute respiratory distress syndrome. Lung protective strategies can reduce many of the adverse mechanistic and biological effects of mechanical ventilation. However, the key modifiable mediators are yet to be defined for the titration of balance between protective ventilation settings and distant organ function. Disparate but complementary mechanisms that may be involved in acute lung-kidney interactions will be discussed. A kidney-lung protective strategy in patients on mechanical ventilation is a potential approach that should be exploited to improve outcomes in critically ill patients.

Video Journal Club 'Cappuccino with Claudio Ronco' at http://www.karger.com/?doi=448471. @ 2016 S. Karger AG, Basel
\end{abstract}

\section{Introduction}

Several efforts have been made in the last decade to address the unacceptably high mortality in patients with acute respiratory distress syndrome (ARDS). Numerous studies suggest that ARDS mortality is declining to 25$40 \%$ mainly not only as a result of improved understanding of its pathophysiology and improvements in supportive care but also due to the implementation of lung protective ventilation strategies $[1,2]$. However, we believe there is room for improvement. A multidisciplinary approach is needed as preventive strategies can be implemented at various stages: during the onset of the predisposing factors, at the onset of ARDS and during mechanical ventilation. The predominant cause of death in ARDS is not hypoxemia, which is one of the defining criteria of ARDS, but multiorgan failure [3]. It is well documented that acute kidney injury (AKI) is the most common organ dysfunction in ARDS patients and that in the presence of AKI the mortality rate increases to more than $40 \%$, with the rate rising with AKI severity $[4,5]$. Therefore, new therapies that can reduce the morbidity and mortality in AKI are

\section{KARGER}

E-Mail karger@karger.com

www.karger.com/bpu
2016 S. Karger AG Basel

$0253-5068 / 16 / 0423-0214 \$ 39.50 / 0$
Faeq Husain-Syed, MD

Department of Internal Medicine II, Division of Pulmonology

Nephrology and Critical Care Medicine, University Clinic Giessen and Marburg

Campus Giessen, Klinikstr. 33, DE-35392 Giessen (Germany)

E-Mail faeqhusain@yahoo.de 
urgently needed. Mechanical ventilation is a life-saving procedure, but it also has many adverse mechanistic and biological effects, and may affect the function of remote organs, including the kidney [6]. We review 4 disparate but complementary mechanisms that may contribute to the adverse outcome in ARDS patients with evidence of renal failure; these mechanisms include fluid overload (FO), cardiogenic pulmonary edema, non-cardiogenic pulmonary edema (and its association with uremic lung and acute lung injury) and, finally, mechanical ventilation in ARDS. Clear understanding of the factors influencing kidney-lung interactions in patients undergoing mechanical ventilation will encourage physicians to explore and develop new strategies for managing critically ill patients.

\section{Fluid Overload}

There is convincing data highlighting cumulative fluid balance as an important vital sign in critically ill patients. Pediatric nephrologists were the first to identify the degree of FO as an independent variable associated with the number of ventilator days and mortality $[7,8]$, and it was established that children with AKI should not be allowed to develop more than $10 \%$ of FO because of the devastating outcomes associated with it [9]. In 2001, Goldstein et al. [7] were the first to assume that '....in some cases, continuous veno-venous hemofiltration may be a prevention, rather than a treatment, for worsening degrees of FO' and 'early initiation of continuous veno-venous hemofiltration to allow for sufficient blood product and nutrition administration, while preventing FO, may improve patient survival'. These findings were followed by multiple reports highlighting the importance of FO in adult intensive care and its association with increased morbidity and mortality [10]. Survivors can be separated from potential non-survivors simply by the degree of FO present on the day of admission and during intensive care unit stay [11]. Bioelectrical impedance vector analysis is an emerging tool to assess total body water in critically ill patients, and recent literature encourages further testing and validation $[11,12]$.

\section{Cardiogenic Pulmonary Edema}

The association between cardiac failure and renal impairment, summarized under the umbrella term cardiorenal syndromes, has gained wide recognition over the last decade [13]. The degree of renal impairment has been shown to be an independent predictor of cardiac prognosis. In type 3 cardiorenal syndrome, AKI can depress cardiac function by several pathophysiological mechanisms other than FO and electrolyte or acid-base disturbances, for example, upregulation of proinflammatory and pro-apoptotic pathways, endothelial dysfunction, myocardial cell infiltration and neurohormonal activation. Systolic/diastolic dysfunction and ventricular arrhythmias are much more frequent in the setting of $\mathrm{AKI}$, and can lead to pulmonary congestion and impairment of the alveolar capillary barrier function, irrespective of intravascular volume [14]. By definition, ARDS is a pulmonary edema that is not fully explained by cardiac failure, though there may be a role of left ventricular dysfunction - in particular of right ventricular dysfunction - considering the high incidence of pulmonary hypertension in ARDS [15]. Venous congestion, as a surrogate for right ventricular impairment, is one of the most important hemodynamic determinants of worsening renal function and is associated with higher mortality $[16,17]$. Experimental models suggest that venous congestion is likely to decrease renal perfusion pressure and oxygen delivery by increasing intracapsular pressure due to the formation of renal edema, which aggravates the renal impairment [18]. This in turn leads to increased pulmonary congestion, pulmonary hypertension, right ventricular overload and reduces left ventricular filling. The consequent increase in central venous pressure is transmitted to the kidney, leading to a positive feedback loop that may culminate in cardiac, pulmonary or renal decompensation, depending on the functional reserve of the respective organs [19].

\section{Noncardiogenic Pulmonary Edema}

It has been recognized for a very long time that lung injury in renal failure has special features. In 1951, Bass et al. [20] described the uremic lung by its 'central butterfly' appearance in the radiograph and associated it with left ventricular failure and advanced kidney disease, but new findings indicate a direct interaction of the lung and the kidney. Unlike cardiogenic pulmonary edema, which is the result of increased capillary hydrostatic pressure and thus theoretically transudative, the uremic lung is characterized by a capillary leak-induced protein-rich pulmonary exudate in the absence of FO [21]. With the introduction of dialysis, the classic presentation of the uremic lung has become rare, although the underlying mechanisms are still operative in ARDS. 
Rabb et al. [22] showed in their rodent model that ischemic AKI can lead to increased pulmonary vascular permeability, cellular apoptosis, alveolar hemorrhage, leukocyte trafficking and alterations in pulmonary gene/protein expression [23]. Delayed recovery of kidney function can impair resolution of lung inflammation post AKI [24]. It is assumed that proinflammatory markers released mostly from necrotic renal tubular cells follow the circulation into the large microcapillary network of the lung and mediate these histological changes. At a cellular level, AKI leads to reduced expression of epithelial sodium channel, sodiumpotassium ATPase and aquaporin 5, all which are essential for alveolar water clearance [22]. Similar mechanisms have been demonstrated in experimental cardiogenic pulmonary edema, including an active augmentation through epithelial chloride secretion (sodium-potassium-chloride cotransporter 1 and cystic fibrosis transmembrane conductance regulator) and secondary fluid flux into the alveolar space [25]. Perhaps the most compelling evidence of lung-kidney interactions is that both organs appear to have similar water and salt channels, and amiloride can reproduce alveolar fluid by inhibition of epithelial sodium channel while furosemide can prevent active alveolar fluid secretion by inhibition of sodium-potassium-chloride cotransporter 1 . This may represent a possible explanation for the rapid and diuresis independent action of furosemide in lung edema, independent of its vasodilating activity. Patients with cardiogenic edema can theoretically improve rapidly with fluid removal, while patients with noncardiogenic pulmonary edema improve little, if at all. In clinical practice, however, most patients fall between the 2 categories, and the concept of keeping the patient 'emptier' is probably better than letting him be 'overfilled'.

\section{Mechanical Ventilation and ARDS}

Mechanical ventilation can be a lifesaving procedure in many clinical settings; however, it can have an adverse impact on hemodynamics and induce systemic inflammation, particularly in patients with injured lungs and kidneys. Mechanical ventilation increases intrathoracic pressure and pulmonary vascular resistance, which may lead to pulmonary hypertension, right ventricular dysfunction and venous congestion. The importance of venous congestion in relation to worsening renal function was reviewed earlier. Physiological studies suggest that the use of positive end-expiratory pressure can activate the neurohormonal system in different ways (via the sympathetic nervous system or disturbances in antidiuretic hormone secretion or the renin-angiotensin system) to further reduce renal blood flow and impede free water clearance and sodium excretion [26, 27]. Hypercapnia and hypoxemia, among other factors, compromise renal blood flow and have been investigated in healthy populations and patients with chronic obstructive pulmonary disease $[28,29]$. Analogous to 'traditional' renal physiological studies [30], Darmon et al. [31] exposed mechanically ventilated ARDS patients without renal failure to different oxygen levels. Patients were studied at baseline (arterial saturation 96\%), then with arterial oxygenation values of $88-90 \%$ (mild hypoxemia) and $98-99 \%$ (high oxygenation). While hemodynamic parameters and blood lactate level did not change during the procedure, creatinine clearance increased during mild hypoxemia and was accompanied by increase in diuresis and the renal resistive index. Clearly, more data are needed to understand the complex pathophysiology of both organs in the setting of mechanical ventilation. Is there a kidneylung protective strategy? And if so, when does mechanical ventilation become injurious to the kidneys or to other organs? For instance, is there an optimal positive endexpiratory pressure level at which ventilation needs are met and renal function is preserved, will any deviation upset the balance?

What we learned from the seminal studies of the ARDSNet group is that compared to patients ventilated with high tidal volumes those ventilated with lower tidal volumes had a $9 \%$ absolute decrease in mortality with more ventilator-free days, less trauma to the injured lungs and less inflammation [32] and less organ failure [33] (especially a markedly reduced incidence of renal failure). Ventilation with high tidal volumes may increase alveolar vascular permeability and thereby increase the risk of proinflammatory mediators translocating into the systemic circulation and causing end-organ damage. Liu et al. [34] demonstrated in a secondary analysis of 876 patient from the ARDS Network trial that elevated levels of interleukin-6, types I and II soluble tumor necrosis factor receptors and plasminogen activator inhibitor-1 were independently associated with AKI. Besides, there is experimental evidence that ventilation with high tidal volumes can induce renal epithelial cell apoptosis [35] and dysregulation of extracellular ligands that help control renal vascular tone and epithelial/endothelial integrity $[36,37]$. For improved management on a ventilator, one of the approaches that should be considered to reduce multiorgan damage is to have more invasive monitoring and attention to hemodynamics, which may decrease kidney injury [38]. 


\section{Conclusions}

Awareness of the multifaceted kidney and lung interactions has increased considerably. Cumulative fluid balance in critically ill patients has to be avoided, not just to prevent static edema but also to decrease edema genesis in those with acute lung injury because of the damaged alveolar capillary barrier. Venous congestion is an important mediator of the cardio-pulmonary-renal axis and may contribute to the poor outcomes associated with ARDS. Decrease in renal function can lead to acute lung injury via multiple biological mechanisms, including downregulation of lung water and salt channels. In the setting of lung-injurious ventilation, mechanical ventilation can be instrumental in amplifying distant organ damage by facilitating the translocation of proinflammatory mediators into the systemic circulation. The implementation of lung-protective ventilation is necessary in patients with ARDS, not just to protect the lungs but to protect the kidneys as well. However, many issues remain unresolved, including the optimal ventilation settings to facilitate lung and distant organ function. To conclude, we believe that there is a kidney-lung protective strategy in mechanical ventilation, and only multidisciplinary care can address the unique needs of patients with ARDS.

\section{Acknowledgments}

The authors thank Drs. Silvia De Rosa and Fiorenza Ferrari for their devoted help.

\section{Disclosure Statement}

The authors do not have any relationship that may be perceived as an actual or possible conflict of interest with the content of manuscript.

\section{Funding}

No funding to declare.

\section{References}

1 Rubenfeld GD, Caldwell E, Peabody E, Weaver J, Martin DP, Neff M, Stern EJ, Hudson LD: Incidence and outcomes of acute lung injury. N Engl J Med 2005;353:1685-1693.

2 Ventilation with lower tidal volumes as compared with traditional tidal volumes for acute lung injury and the acute respiratory distress syndrome. The acute respiratory distress syndrome network. N Engl J Med 2000;342: 1301-1308.

3 Del Sorbo L, Slutsky AS: Acute respiratory distress syndrome and multiple organ failure. Curr Opin Crit Care 2011;17:1-6.

4 Soto GJ, Frank AJ, Christiani DC, Gong MN: Body mass index and acute kidney injury in the acute respiratory distress syndrome. Crit Care Med 2012;40:2601-2608.

5 Darmon M, Clec'h C, Adrie C, Argaud L, Allaouchiche B, Azoulay E, Bouadma L, Garrouste-Orgeas M, Haouache $\mathrm{H}$, Schwebel C, Goldgran-Toledano D, Khallel H, Dumenil AS, Jamali S, Souweine B, Zeni F, Cohen Y, Timsit JF: Acute respiratory distress syndrome and risk of AKI among critically ill patients. Clin J Am Soc Nephrol 2014;9:1347-1353.

6 Husain-Syed F, Slutsky AS, Ronco C: Lungkidney crosstalk in the critically ill patient. Am J Respir Crit Care Med 2016, Epub ahead of print.

7 Goldstein SL, Currier H, Graf CD, Cosio CC, Brewer ED, Sachdeva R: Outcome in children receiving continuous venovenous hemofiltration. Pediatrics 2001;107:1309-1312.
8 Valentine SL, Sapru A, Higgerson RA, Spinella PC, Flori HR, Graham DA, Brett M, Convery M, Christie LM, Karamessinis L, Randolph AG; Pediatric Acute Lung Injury and Sepsis Investigator's (PALISI) Network; Acute Respiratory Distress Syndrome Clinical Research Network (ARDSNet): Fluid balance in critically ill children with acute lung injury. Crit Care Med 2012;40:28832889.

9 Arikan AA, Zappitelli M, Goldstein SL, Naipaul A, Jefferson LS, Loftis LL: Fluid overload is associated with impaired oxygenation and morbidity in critically ill children. Pediatr Crit Care Med 2012;13:253-258.

10 Boyd JH, Forbes J, Nakada TA, Walley KR, Russell JA: Fluid resuscitation in septic shock: a positive fluid balance and elevated central venous pressure are associated with increased mortality. Crit Care Med 2011;39: 259-265.

11 Basso F, Berdin G, Virzì GM, Mason G, Piccinni P, Day S, Cruz DN, Wjewodzka M, Giuliani A, Brendolan A, Ronco C: Fluid management in the intensive care unit: bioelectrical impedance vector analysis as a tool to assess hydration status and optimal fluid balance in critically ill patients. Blood Purif 2013; 36:192-199.

12 Samoni S, Vigo V, Reséndiz LI, Villa G, De Rosa S, Nalesso F, Ferrari F, Meola M, Brendolan A, Malacarne P, Forfori F, Bonato R, Donadio C, Ronco C: Impact of hyperhydra- tion on the mortality risk in critically ill patients admitted in intensive care units: comparison between bioelectrical impedance vector analysis and cumulative fluid balance recording. Crit Care 2016;20:95.

13 Ronco C, Haapio M, House AA, Anavekar N, Bellomo R: Cardiorenal syndrome. J Am Coll Cardiol 2008;52:1527-1539.

14 Kelly KJ: Distant effects of experimental renal ischemia/reperfusion injury. J Am Soc Nephrol 2003;14:1549-1558.

15 Bull TM, Clark B, McFann K, Moss M; National Institutes of Health/National Heart, Lung, and Blood Institute ARDS Network: Pulmonary vascular dysfunction is associated with poor outcomes in patients with acute lung injury. Am J Respir Crit Care Med 2010; 182:1123-1128.

16 Damman K, van Deursen VM, Navis G, Voors AA, van Veldhuisen DJ, Hillege HL: Increased central venous pressure is associated with impaired renal function and mortality in a broad spectrum of patients with cardiovascular disease. J Am Coll Cardiol 2009;53:582-588.

17 Legrand M, Dupuis C, Simon C, Gayat E, Mateo J, Lukaszewicz AC, Payen D: Association between systemic hemodynamics and septic acute kidney injury in critically ill patients: a retrospective observational study. Crit Care 2013;17:R278.

18 Bellomo R, Prowle JR, Echeverri JE: Diuretic therapy in fluid-overloaded and heart failure patients. Contrib Nephrol 2010;164:153-163. 
19 Husain-Syed F, McCullough PA, Birk HW, Renker M, Brocca A, Seeger W, Ronco C: Cardio-pulmonary-renal interactions: a multidisciplinary approach. J Am Coll Cardiol 2015;65:2433-2448.

20 Bass HE, Greenberg D, Singer E, Miller MA: Pulmonary changes in uremia. Bull N Y Acad Med 1951;27:397.

21 Faubel S, Edelstein CL: Mechanisms and mediators of lung injury after acute kidney injury. Nat Rev Nephrol 2016;12:48-60.

22 Rabb H, Wang Z, Nemoto T, Hotchkiss J, Yokota N, Soleimani M: Acute renal failure leads to dysregulation of lung salt and water channels. Kidney Int 2003;63:600-606.

23 Ko GJ, Rabb H, Hassoun HT: Kidney-lung crosstalk in the critically ill patient. Blood $\mathrm{Pu}$ rif 2009;28:75-83.

24 Andres-Hernando A, Altmann C, Bhargava R, Okamura K, Bacalja J, Hunter B, Ahuja N, Soranno D, Faubel S: Prolonged acute kidney injury exacerbates lung inflammation at 7 days post-acute kidney injury. Physiol Rep 2014;2:pii:e12084.

25 Solymosi EA, Kaestle-Gembardt SM, Vadász I, Wang L, Neye N, Chupin CJ, Rozowsky S, Ruehl R, Tabuchi A, Schulz H, Kapus A, Morty RE, Kuebler WM: Chloride transportdriven alveolar fluid secretion is a major contributor to cardiogenic lung edema. Proc Natl Acad Sci U S A 2013;110:E2308-E2316.

26 Annat G, Viale JP, Bui Xuan B, Hadj Aissa O, Benzoni D, Vincent M, Gharib C, Motin J: Effect of PEEP ventilation on renal function, plasma renin, aldosterone, neurophysins and urinary $\mathrm{ADH}$, and prostaglandins. Anesthesiology 1983;58:136-141.

27 Sharkey RA, Mulloy EM, Long M, O’Neill SJ: The effect of continuous positive airway pressure (CPAP) on renal vascular resistance: the influence of renal denervation. Crit Care 1999;3:33-37.

28 Olsen NV: Effect of hypoxaemia on water and sodium homeostatic hormones and renal function. Acta Anaesthesiol Scand Suppl 1995; 107:165-170.

29 Sharkey RA, Mulloy EM, O’Neill SJ: The acute effects of oxygen and carbon dioxide on renal vascular resistance in patients with an acute exacerbation of COPD. Chest 1999;115: 1588-1592.

30 Hildebrandt W, Ottenbacher A, Schuster M, Swenson ER, Bärtsch P: Diuretic effect of hypoxia, hypocapnia, and hyperpnea in humans: relation to hormones and $\mathrm{O}(2)$ chemosensitivity. J Appl Physiol (1985) 2000;88: 599-610.

31 Darmon M, Schortgen F, Leon R, Moutereau S, Mayaux J, Di Marco F, Devaquet J, BrunBuisson C, Brochard L: Impact of mild hypoxemia on renal function and renal resistive index during mechanical ventilation. Intensive Care Med 2009;35:1031-1038.

32 Ranieri VM, Suter PM, Tortorella C, De Tullio R, Dayer JM, Brienza A, Bruno F, Slutsky AS: Effect of mechanical ventilation on inflammatory mediators in patients with acute respiratory distress syndrome: a randomized controlled trial. JAMA 1999;282: 54-61.
33 Ranieri VM, Giunta F, Suter PM, Slutsky AS: Mechanical ventilation as a mediator of multisystem organ failure in acute respiratory distress syndrome. JAMA 2000;284:43-44.

34 Liu KD, Glidden DV, Eisner MD, Parsons PE, Ware LB, Wheeler A, Korpak A, Thompson BT, Chertow GM, Matthay MA; National Heart, Lung, and Blood Institute ARDS Network Clinical Trials Group: Predictive and pathogenetic value of plasma biomarkers for acute kidney injury in patients with acute lung injury. Crit Care Med 2007;35:2755-2761.

35 Imai Y, Parodo J, Kajikawa O, de Perrot M, Fischer S, Edwards V, Cutz E, Liu M, Keshavjee S, Martin TR, Marshall JC, Ranieri VM, SLutsky AS: Injurious mechanical ventilation and end-organ epithelial cell apoptosis and organ dysfunction in an experimental model of acute respiratory distress syndrome. JAMA 2003;289:2104-2112.

36 Douillet CD, Robinson WP 3rd, Zarzaur BL, Lazarowski ER, Boucher RC, Rich PB: Mechanical ventilation alters airway nucleotides and purinoceptors in lung and extrapulmonary organs. Am J Respir Cell Mol Biol 2005; 32:52-58.

37 Koyner JL, Murray PT: Mechanical ventilation and the kidney. Blood Purif 2010;29:5268.

38 Hoag JB, Liu M, Easley RB, Britos-Bray MF, Kesari P, Hassoun H, Haas M, Tuder RM, Rabb H, Simon BA: Effects of acid aspirationinduced acute lung injury on kidney function. Am J Physiol Renal Physiol 2008;294:F900F908. 